\title{
Definition and review on a category of long non-coding RNA: Atherosclerosis-associated circulating IncRNA (ASCLncRNA)
}

\author{
Shanshan Lu ${ }^{1}$, Qin Liang ${ }^{1}$, Yanqing Huang ${ }^{1}$, Fanming Meng ${ }^{\text {Corresp., } 2}$, Junwen Liu ${ }^{\text {Corresp. 1, } 3}$ \\ ${ }^{1}$ Department of Histology and Embryology, School of Basic Medical Science, Central South University, Changsha, Hunan Province, China \\ 2 Forensic Science, School of Basic Medical Science, Central South University, Changsha, Hunan Province, China \\ 3 China-Africa Research Center of Infectious Diseases, School of Basic Medical Sciences, Central South University, Changsha, Hunan Province, China \\ Corresponding Authors: Fanming Meng, Junwen Liu \\ Email address: 22018112@csu.edu.cn, liujunwen@csu.edu.cn
}

Atherosclerosis (AS) is one of the most common cardiovascular system diseases, which seriously affects public health in modern society. Finding potential biomarkers in the complicated pathological progression of AS is of great significance for the prevention and treatment of AS. Studies have shown that long noncoding RNAs (IncRNAs) can be widely involved in the regulation of many physiological processes, and have important roles in different stages of AS formation. LncRNAs can be secreted into the circulatory system through exosomes, microvesicles, and apoptotic bodies. Recently, increasing studies have been focused on the relationships between circulating IncRNAs and AS development. The IncRNAs in circulating blood are expected to be new non-invasive diagnostic markers for monitoring the progression of AS. We briefly reviewed the previously reported IncRNA transcripts which related to AS development and detectable in circulating blood, including ANRIL, SENCR, CoroMarker, LIPCAR, HIF1 $\alpha$-AS1, LnCRNA H19, APPAT, KCNQ1OT1, LnCPPARS, LinCRNA-p21, MALAT1, MIAT, and UCA1. Further researches and a definition of atherosclerosis-associated circulating IncRNA (ASCLnCRNA) were also discussed. 
1 Definition and review on a category of long non-coding

2 RNA: Atherosclerosis-associated circulating IncRNA

3 (ASCLncRNA)

4

5

6 7

Shanshan $\mathrm{Lu}^{1}$, Qin Liang ${ }^{1}$, YanQing Huang ${ }^{1}$, FanMing Meng ${ }^{2}$, Junwen Liu ${ }^{1,3}$

${ }^{1}$ Department of Histology and Embryology, School of Basic Medical Science, Central South University, Changsha, Hunan 410013, China

${ }^{2}$ Forensic Science, School of Basic Medical Science, Central South University, Changsha, Hunan 410013, China

${ }^{3}$ China-Africa Research Center of Infectious Diseases, School of Basic Medical Sciences, Central South University, Changsha, Hunan 410000, China.

Corresponding Author:

Junwen Liu ${ }^{1}$, FanMing Meng ${ }^{2}$,

Tongzipo Road, Yuelu District, Medical College of Xiangya, Changsha City, Hunan Province, 410013, China

Email address: liujunwen@csu.edu.cn; 22018112@,csu.edu.cn

\section{Abstract}

Atherosclerosis (AS) is one of the most common cardiovascular system diseases, which seriously affects public health in modern society. Finding potential biomarkers in the complicated pathological progression of AS is of great significance for the prevention and treatment of AS. Studies have shown that long noncoding RNAs (lncRNAs) can be widely involved in the regulation of many physiological processes, and have important roles in different stages of AS formation. LncRNAs can be secreted into the circulatory system through exosomes, microvesicles, and apoptotic bodies. Recently, increasing studies have been focused on the relationships between circulating lncRNAs and AS development. The lncRNAs in circulating blood are expected to be new non-invasive diagnostic markers for monitoring the progression of 
33 AS. We briefly reviewed the previously reported lncRNA transcripts which related to AS

34 development and detectable in circulating blood, including ANRIL, SENCR, CoroMarker,

35 LIPCAR, HIF1 $\alpha$-AS1, LncRNA H19, APPAT, KCNQ1OT1, LncPPAR $\delta$, LincRNA-p21, MALAT1,

$36 M I A T$, and $U C A 1$. Further researches and a definition of atherosclerosis-associated circulating

37 lncRNA (ASCLncRNA) were also discussed.

38

Keywords: atherosclerosis; biomarker; circulating lncRNAs; non-invasive diagnosis; ASCLncRNA

AMI: acute myocardial infarction

ANRIL: CDKN2B antisense RNA 1

APPAT: atherosclerotic plaque pathogenesis associated transcript

AS: atherosclerosis

ASCLncRNA: atherosclerosis-associated circulating lncRNA

BRG1: Brahma-related gene 1

CAD: coronary artery disease

ceRNA: competing endogenous RNA

ECs: endothelial cells

$\mathrm{HF}$ : heart failure

HIF1A-AS1: LncRNA HIF 1 alpha-antisense RNA 1

LncPPAR $\delta$ : long noncoding Peroxisome proliferator-activated receptor delta lncRNAs: long noncoding RNAs

MALAT1: Metastasis-associated lung adenocarcinoma transcript 1

MIAT: myocardial infarction associated transcript miRNAs: microRNAs qPCR: quantitative Polymerase Chain Reaction

SENCR: smooth muscle and endothelial cell-enriched migration/ differentiation-associated long noncoding RNA

61 SMCs: smooth muscle cells

62 SNPs: single nucleotide polymorphisms

UCA1: urothelial carcinoma associated 1

VSMCs: vascular smooth muscle cells 


\section{Introduction}

Cardiovascular diseases (CVDs) seriously endanger human health around the world, taking the lives of around 17.9 million each year (WHO. 2017), which place a heavy financial burden on society and families. Atherosclerosis (AS) is the most common cause of CVDs (Sanada et al. 2018). Although it's an asymptomatic condition, the accumulation and rupture of atheromatous plaques in arteries can lead to serious consequences, such as coronary artery diseases (CADs), acute myocardial infarction (AMI), and heart failure (HF), etc (Harada et al. 2014; Libby et al. 2011). Plaque rupture is responsible for $75 \%$ of AMI with highest incidence occurs in male beyond age 45 and female beyond age 50 (Pahwa. \& Jialal. 2019). The AS progression involves dynamic changes in the vessel wall, such as endothelial dysfunction, macrophage activation, and phenotypic changes of vascular smooth muscle cells (VSMCs) (Xi et al. 2013).

Compared with other morbid states, AS is characterized by small lesions and insidious onset. At present, the diagnosis of AS is based on a combination of multiple detection methods, such as echocardiography, electrocardiogram, computed tomography scan, blood test, and angiography (NHLBI. 2020). However, the confirmed diagnosis of AS depends on surgery and pathological examination (like carotid endarterectomy), which can be traumatic and risky for patients. Considering the difficulty of detection on such subtle changes in vivo, identifying potential biomarkers associated with the complex pathological progress of AS is essential for the prevention and treatment of AS.

Long noncoding RNAs (lncRNAs) are defined as transcripts >200 bp without proteincoding potential. It was previously considered to be the "noise" or "junk" of the genome and have no substantive function (Palazzo \& Lee 2015). Recent researches, however, found that lncRNAs functions in various kinds of cellular activities, which are related to many serious human diseases (Wapinski \& Chang 2011). LncRNAs can target microRNAs (miRNAs) to form the competing endogenous RNA (ceRNA) axes and then function in different stages of AS development ( $\mathrm{Li}$ et al. 2016; Salmena et al. 2011). They not only exist in cells but can also be detected in plasma or serum samples, which are called circulating lncRNAs (Cao et al. 2019; Wang et al. 2017). Circulating lncRNAs show great resistance to endogenous RNase, which 
makes them more stable in blood samples (Tong et al. 2015). All of these provide the necessary basis for finding circulating lncRNA as potential biomarkers in AS prevention and treatment.

In this review, we briefly discuss current advances of circulating lncRNAs in AS, which aim to facilitate our understanding of the relationships between them and promote the development of circulating lncRNAs as predicting AS biomarkers for clinical applications.

\section{Survey methodology}

Our team put the focus on advances in the relationship between epigenetics and CVDs. We performed the literature search mainly using the PubMed database (https://www.ncbi.nlm.nih.gov/pubmed/), Web Of Science (www.webofknowledge.com), and Google scholar (scholar.google.cn). Based on the main keywords-"atherosclerosis", "coronary artery disease (or CAD)", "heart failure" and "stroke" combined with "IncRNA", "blood", "serum”, or "plasma”, “exosome”, “microvesicle", "apoptotic body”, relevant articles are extracted to classify and summarize the potential atherosclerosis-associated circulating lncRNAs. According to the search strategy, a total of 285 literatures were identified, including 55 reviews and 6 clinical trials. 282 of them have the full text. After reading the abstract and screening, 109 were then included which satisfied our goal. We did not refine factors such as journal, publishing date, or journal impact factors during our search. Ultimately, the time span of references in this review is from 1993 to 2020.

\section{Circulating IncRNAs}

Ideal biomarker refers to those molecules that can be used in non-invasive detection with relative stability, detection sensitivity, and specificity (Qi et al. 2016; Shi \& Yang 2016). But so far, lncRNAs used in scientific researches were usually derived from atherosclerotic plaques based on interventional methods (Roth \& Diederichs 2016). With the rapid improvements of detection methods, recent studies show that lncRNAs can be stably detected from body fluids (Panzitt et al. 2007; Reis \& Verjovski-Almeida 2012; Tinzl et al. 2004). LncRNAs can be secreted from tumor cells, then move into the circulatory system through exosomes, 
122 microvesicles, and apoptotic bodies, thus becoming a novel non-invasive diagnostic marker for monitoring the progression of cancers (Wang et al. 2019a). The variation of cellular components in blood-vessel cells during the development of AS make it possible for lncRNAs to migrate into the circulatory system (Monteiro et al. 2019).

Blood is the most widely distributed body fluid, carrying oxygen, nutrients, and signaling molecules to tissues and organs throughout the body. The circulating blood emphasizes a state of blood fluid distributing in the circulatory system of human body. Dynamic changes of particular substance in the blood may be closely related to specific disease states, such as cancers, CVDs, and nervous system diseases (Chen et al. 2017; Fridman et al. 2017; Wang et al. 2018). Such biomarkers can provide the following information: (1) identifying and classifying patient's condition; (2) diagnosing and monitoring disease states; and (3) guiding doctors to make appropriate therapeutic schedules and prognosis observations (Heil \& Tang 2015). The properties of lncRNAs determine their potential as biomarkers, such as lncRNA PCA3 in prostate cancer, and lncRNAs UCA1 in bladder cancer. Both of them can be easily detected in urine samples, and even have special discriminations for cancer types (Hessels et al. 2003; Wang et al. 2006). Later, lncRNAs with biomarker function in circulating blood were found in gastric cancer, lung cancer and breast cancer (Dong et al. 2015; Liang et al. 2016; Zhang et al. 2016).

AS is one of the most common diseases in the world. Studies on the correlation between circulating lncRNAs and AS development have been reported in recent years (Chi et al. 2017; Pan et al. 2019; Wang et al. 2017). If pathological changes of vessel can be found in the early stage based on the detection of circulating lncRNAs, it will be shade light on the initial intervention and treatment to reducing the morbidity and mortality of patients.

\section{ASCLncRNA: atherosclerosis-associated circulating IncRNA}

\subsection{ANRIL (CDKN2B antisense RNA 1)}

$A N R I L$, also known as $C D K N 2 B-A S 1$, is located at chromosome 9p21 (Pasmant et al. 2007). The ANRIL gene contains 19 exons and can be transcribed into many spliceosomes with tissue specificity (Folkersen et al. 2009). Genome-wide association analysis (GWAS) revealed many disease-associated single nucleotide polymorphisms (SNPs) at the 9p21 locus (Pasmant et al. 2011). These SNPs are closely associated with the severity of coronary AS, cervical AS, peripheral arterial disease. (Congrains et al. 2012; Holdt et al. 2010; Holdt \& Teupser 2012). 
152

153

154

155

156

157

158

159

160

161

162

163

164

165

166

167

168

169

170

171

172

173

174

175

176

177

178

179

180

181

182

ANRIL exists in many AS-associated cells and tissues, such as VSMCs, endothelial cells (ECs), monocytes, macrophages, and carotid tissues. It plays a trans-regulatory role through binding to Alu elements in the promoter region of target genes, which is involved in the regulation of fatty acids, glucose metabolism, and inflammatory responses (Bochenek et al. 2013; Holdt et al. 2013).

In a sequencing analysis of whole blood samples from patients with AMI, researchers detected $A N R I L$ 's significant reduction and selected it as a self-labeling molecule (Vausort et al. 2014). This is the first report on the dynamic expression level of $A N R I L$ in circulating blood. Another research exhibits that $A N R I L$ was up-regulated in peripheral venous blood from patients of type 2 diabetes mellitus complicated with AMI (Zhang \& Wang 2019). Recently, circulating ANRIL was found to increase in the plasma of CAD patients compared with the controls and showed promise as a good diagnostic value for CAD because it could be related to the severity of inflammation, stenosis degree, and prognosis ( $\mathrm{Hu} \& \mathrm{Hu} 2019)$. The differences in research objects, such as arterial blood vs. venous blood, and the existence of comorbidity may be the core reason for the opposite results. Since the mechanism of ANRIL's function in the development of AS is not very clear, its role as a biomarker in circulating blood remains to be explored.

\subsection{SENCR (smooth muscle and endothelial cell-enriched migration/ differentiation-associated long noncoding RNA)}

SENCR is a specifically cytoplasmic lncRNA enriched in vascular cells. It was firstly discovered in the high-throughput sequencing of human coronary artery SMCs (Bell et al. 2014). Bell and colleagues found SENCR seems to play a role in inhibiting phenotypic transformation and cell proliferation of VSMCs through downregulating the cell contraction-related gene (Myocd) and upregulating the promigration-associated genes (Mdk/Ptn) (Bell et al. 2014). It can inhibit the pathological migration of VSMCs to neointima during AS formation. Besides, SENCR could also bind CKAP4, a cytosolic protein in ECs, through a noncanonical RNA-binding domain. This interplay helps maintain the adherent junctions, membrane integrity, and permeability of ECs, thus protecting against AS (Lyu et al. 2019). The expression level of SENCR, which was isolated from the vessel wall ECs of patients with CVDs, was much lower than the control. It suggests that SENCR may be decreased in patients with endothelial dysfunction or AS (Boulberdaa et al. 2016). The decline of this atheroprotective lncRNA may 
provide a warning for the onset of AS.

By using amplification refractory mutation system-polymerase chain reaction, SENCR can be detected stably and sensitively in blood samples of patients with CAD (Shahmoradi et al. 2017). Besides, a large-scale investigation focused on the effect of pioglitazone on type 2 diabetes found that the expression of $S E N C R$ in the blood is related to the evaluation of diastolic function after drug treatment, and that its indication in drug treatment effect is better than other existing indicators (de Gonzalo-Calvo et al. 2016b).

\subsection{CoroMarker (Aldo-keto reductase family 1 member B1 pseudogene 3)}

Yang et al. screened 174 differentially expressed lncRNA transcripts in blood samples from CAD patients and healthy people through microarray analysis, then they further chose five candidate lncRNAs by improving screening criteria and verified them by quantitative Polymerase Chain Reaction (qPCR) technology. Receiver operating characteristic (ROC) curve analysis indicated that lncRNA $A C 100865.1$ could meet the requirements of biomarkers and was named CoroMarker. Better sensitivity and predictive effects can be obtained when combined with other risk factors of CVDs (Yang et al. 2015). CoroMarker has now been demonstrated to be distributed in vesicles of circulating blood and monocytes. Knockdown of CoroMarker in THP-1 cells caused significant down-regulation of IL-1 $\beta$, IL-6, and TNF- $\alpha$, suggesting that CoroMarker may play an important role in the inflammatory response of AS (Cai et al. 2016b).

\subsection{LIPCAR (mitochondrially encoded long non-coding cardiac associated RNA)}

LIPCAR showed opposite expression trend before and after the AMI event; it was downregulated at the early stage of AMI, but gradually increased in the subsequent period (Kumarswamy et al. 2014). Surprisingly, it was released from the mitochondrion in blood cells rather than cardiac cells, which may be the reason for the changes in LIPCAR expression in different stages of AMI (Schulte et al. 2019). Meng and colleagues investigated diagnostic value of 9 circulating lncRNAs in ST-segment elevation myocardial infarction and found that LIPCAR had better diagnostic accuracy than others (Li et al. 2018a).

In plasma, the expression of LIPCAR was inversely proportional to high-density lipoprotein cholesterol, suggesting it may lead to dyslipidemia, which is a key factor in the progression of AS (Zhang et al. 2017). Besides, overexpression of LIPCAR induced by the treatment of ox-LDL or platelet-derived growth factor BB could promote the proliferation, migration, and phenotypic transition of VSMCs, which proved the function of LIPCAR in the progression of AS (Wang et 
214 al. 2019c). The possibility of LIPCAR as biomarkers for CVDs was also confirmed by other

215 studies (de Gonzalo-Calvo et al. 2016a; Santer et al. 2019). These may lay the theoretical basis

216 for the use of LIPCAR as a biomarker for AS.

217

218

219

220

221

222

223

224

225

226

227

228

229

230

231

232

233

234

235

236

237

238

239

240

241

242

243

\subsection{HIF1A-AS1 (HIF1A antisense RNA 1)}

Brahma-related gene $1(B R G 1)$ is a central catalytic subunit in many chromatin-modifying enzymatic complexes and is involved in the regulation of gene expression through chromatin remodeling (Zhou et al. 2009). HIFIA-ASI was found to be correlated with BRG1 in VSMCs detected by microarray in $B R G 1$ gain- and loss-of-function experiment. The interaction between them regulates the proliferation and apoptosis of VSMCs in vitro. (Wang et al. 2015c). The function of HIF1A-AS1 in VSMCs was confirmed by Xu et al. that its overexpression could inhibit cell proliferation (Xu et al. 2019). Silencing of HIFIA-ASI could promote the proliferation and reduce the hyperlipidemia-induced apoptosis of human umbilical vein ECs (Wang et al. 2015b). The potential role of HIFIA-AS1 as a biomarker in circulating blood has already been verified in several cancers such as colorectal carcinoma and non-small cell lung cancer (Gong et al. 2017; Tantai et al. 2015). Both Zhao and Xu testified that expression of HIF1A-AS1 was dramatically increased in the blood of patients with aneurysm (Xu et al. 2019; Zhao et al. 2014). HIFIA-ASI was also up-regulated in the exosomes extracted from the plasma sample of patients with AS, which was thought to be the result of the activation of VSMCs and ECs (Wang et al. 2017). These studies laid a foundation for the clinical application of HIF 1A$A S 1$ in the AS diagnosis, but also ruled out its usage as a biomarker alone.

\subsection{LncRNA H19 (H19 imprinted maternally expressed transcript)}

LncRNA H19 is located near the insulin-like growth factor 2(IGF2) gene in an imprinted region of chromosome 11 (Giannoukakis et al. 1993). The common polymorphisms of lncRNA $H 19$ were related to the risk and hazard level of CAD in a Chinese population (Gao et al. 2015). By using short hairpin RNA (shRNA) in ox- LDL-treated Raw264.7 cells, Han demonstrated that miR-130b is an important target gene of $\operatorname{lncRNA~H19}$. The axis could regulate inflammation response and lipid metabolism, which could be used as a targeting site of treating AS (Han et al. 2018a). Another experiment conducted by Zhang indicated that lncRNA H19 acts as a ceRNA of miR-148b and thus modulates the $\mathrm{WNT} / \beta$-catenin signaling pathway to promote proliferation and suppress apoptosis of ox-LDL-stimulated VSMCs(Zhang et al. 2018a). Up to now, the 
244

245

246

247

248

249

250

251

252

253

254

255

256

257

258

259

260

261

262

263

264

265

266

267

268

269

270

271

272

273

expression level of $\mathrm{H} 19$ in the serum of patients with AS was all found to be up-regulated (Cao et al. 2019; Han et al. 2018a; Pan 2017; Zhang et al. 2018a).

\subsection{APPAT (atherosclerotic plaque pathogenesis associated transcript)}

The newly reported lncRNA $A P P A T$ also shows potential predictive function for AS progression. APPAT is a $669 \mathrm{bp}$ intergenic long non-coding RNA containing four exons and localized in human chromosome 2. APPAT was found to be mainly distributed in the middle layer of the coronary vessel wall and located on the cytoplasmic region of VSMCs via immunofluorescence (Meng et al. 2018).

$A P P A T$ was discovered in blood samples. It declined inconspicuously in patients with angina pectoris (AP) through the method of case-control matching, whereas significantly downregulated in AMI patients compared with the normal group. Further examination revealed a decrease in APPAT expression in tissues of severely stenotic coronary arteries. This detectable trend in blood, independent of disease factors such as diabetes and hypertension, has potential value for predicting and monitoring the development of AS (Meng et al. 2018).

\subsection{KCNQ10T1 (KCNQ1 opposite strand/antisense transcript 1)}

Studies have shown that lncRNAs can affect the transcriptional activities of multiple genes by interacting with chromatin (Saxena \& Carninci 2011). The Kcnq1 locus spans more than 1 $\mathrm{Mb}$ on the chromosome and is located on the short arm of human chromosome 11 (11p15.5), containing 8-10 protein-coding genes and lncRNA KCNQ1OT1 (Paulsen et al. 1998). Through recruiting chromatin and DNA-modifying proteins, KCNQ1OT1 interacts with chromatin to form a complex folding structure and then silences multiple target genes in this region (Kanduri 2011).

The expression of KCNQ1OT1 in atheromatous plaques was negatively correlated with the age of patients, laying the foundation for further revealing the association between age and atheromatous plaques (Arslan et al. 2017). Lately, it is also verified to be elevated in the peripheral blood monocytes of patients with CAD and blood samples of MI patients, which suggests its role in the diagnosis of AS (Zhang et al. 2019).

\subsection{LnCPPARס (long noncoding peroxisome proliferator-activated receptor delta)}

$P P A R \delta$ belongs to the nuclear receptor superfamily (Giordano Attianese \& Desvergne 2015). Activation of $P P A R \delta$ increases the cholesterol efflux of macrophages, inhibits the transmembrane migration activity of leukocytes or monocytes to the inner wall of arteries, and 
274 reduces the size of atheromatous plaques (Ehrenborg \& Skogsberg 2013). Cai and colleagues

275 isolated a lncRNA transcript, NONHSAT112178, from the plasma of CAD patients and named it

276 as $L n c P P A R \delta$, which is located near the $P P A R \delta$. They further reported that the expression of

$277 P P A R \delta$ decreased significantly in THP-1 cells after the knock down $L n c P P A R \delta$, indicating that

$278 L n c P P A R \delta$ may be involved in $P P A R \delta$-mediated inflammatory signaling pathway and play a role

279 in the progression of AS and CAD. In the plasma test results, LncPPAR $\delta$ expression is up-

280 regulated in CAD patients and is shown to exist stably in the blood. When combined with factors

281 such as gender and age, $L n c P P A R \delta$ showed better predictive function for CAD patients (Cai et al. 282 2016a).

283

284

285

286

287

288

289

290

291

292

293

294

295

296

297

298

299

300

301

302

303

\subsection{LincRNA-p21 (tumor protein p53 pathway corepressor 1)}
LincRNA-p21 was firstly discovered in mice (Huarte et al. 2010). It interacts with heterogeneous nuclear ribonucleoprotein $\mathrm{K}$ (hnRNP-K), the repressive complex of $p 53$, and then affects the expression of $p 53$ 's downstream target genes (Barichievy et al. 2018). Wu et al. found that it inhibits cell proliferation and helps bring about neointimal formation in damaged coronary arteries, thus affecting the progression of AS in mice. They also discovered that down-regulation of LincRNA-p21 in human VSMCs can also promote cell proliferation and inhibit apoptosis ( $\mathrm{Wu}$ et al. 2014). Hu et al. found that overexpression of LincRNA-p21 shows the opposite trends in VSMCs (Hu et al. 2019a). These two consistent results suggested that LincRNA-p21 may play a protective role against AS. Cekin et al. found that LincRNA-p21 decreased about 7 fold in atherosclerotic coronary artery tissues compared with the normal arterials in the same individuals (Cekin et al. 2018). The application of circulating LincRNA-p21 exhibits a well predictive power on brain carotid tumors, chronic hepatitis (Fayda et al. 2016; Yu et al. 2017), and thoracic aortic aneurysms (Hu et al. 2019a). Although there is no direct evidence indicating the link between circulating LincRNA-p21 with the progression of AS, it is reasonable to infer that circulating LincRNA-p21 could also work as a marker for identifying AS given its effect on VSMCs when combined with other diagnostic indicators.

\subsection{MALAT1 (metastasis associated lung adenocarcinoma transcript 1)}

MALAT1, also known as Neat2, was firstly demonstrated to be related to the metastasis of non-small cell lung cancer (Ji et al. 2003). It binds with polycomb 2 to regulate the proliferation of cells by relocating growth-control gene loci (Yang et al. 2011). Michalik et al. verified the 
304

305

306

307

308

309

310

311

312

313

314

315

316

317

318

319

320

321

322

323

324

325

326

327

328

329

330

331

332

significant function of MALATI in the balancing of the phenotype of ECs, which affects vascular growth in vivo (Michalik et al. 2014). It could act as ceRNAs with miRNAs (such as miR-216a$5 \mathrm{p}$ and miR-155) to inhibit inflammatory cytokine release and promote cell autophagy in ECs (Li et al. 2018b; Wang et al. 2019b).

MALAT1 was also found to be expressed highly in the macrophages of rats with diabetic AS (Han et al. 2018b), the plasma of patients with acute cerebral infarction (Teng \& Meng 2019), and serum of AS patients (Wang et al. 2019b). This can be partially explained by the increase of MALAT1 expression in exosomes secreted by ECs (Gao et al. 2019). Surprisingly, the expression is downregulated in both human and mouse atherosclerotic plaques (Arslan et al. 2017; Cremer et al. 2019). We hypothesize that the high expression of MALAT1 in serum and exosomes originates from the cells surrounding pathological tissues and thus cause a decline in plaques. However, Li and colleagues found lower expression of MALAT1 in exosomes of ox-LDL-treated ECs compared with the normal ECs ( $\mathrm{Li}$ et al. 2019). This difference suggests that the role of MALATI in AS remains unclear and deserves a multi-center investigation.

\subsection{MIAT (myocardial infarction associated transcript)}

MIAT was found in an SNP-rich region related to AMI. A small change in a single SNP locus can cause an up-regulation of MIAT expression levels (Ishii et al. 2006). Knockdown of MIAT in ECs can inhibit cell proliferation and migration in vitro (Yan et al. 2015). The expression of MIAT increased in blood samples of AS patients, while its target miR-181b was down-regulated. Further studies found that a ceRNA axis--MIAT-miR-181b-STAT3 --in aortic SMCs may participate in cell proliferation and apoptosis and then affect the occurrence and development of AS (Zhong et al. 2018). The same expression trend was verified in the AS mice model, where MIAT inhibits efferocytosis through targeting the miR-149-5p/CD47 to regulate plaque vulnerability (Ye et al. 2019). The MIAT-based ceRNA pattern provides a potential target for therapy of AS.

\subsection{UCA1 (urothelial carcinoma associated 1)}

$U C A 1$ was originally identified as a highly specific and sensitive biomarker of bladder transitional cell carcinoma, which can be detected from urine (Wang et al. 2006). It could promote glucose metabolism, lactic acid production, cell proliferation, and inhibit apoptosis of 
333 bladder cancer cells (Li et al. 2014; Wang et al. 2008). The functions of UCA1 was later

334 explored in other cells. For example, it could protect cardiomyocytes from $\mathrm{H}_{2} \mathrm{O}_{2}$-induced

335 apoptosis by targeting miR-1(Yan et al. 2016). In cardiovascular diseases, Yin et al. found that

336 the silencing of UCA1 could induce apoptosis and repress the viability, migration, tube formation

337 of human microvascular ECs (Yin et al. 2018). Hu et al. found that the knockdown of UCA1 in

338 THP-1 cells could repress the formation of foam cells and restrain the total cholesterol and

339 triglyceride levels via sponging miR-206 (Hu et al. 2019b). Moreover, a stable presence of

340 UCA1 was also detected in circulating blood and serum exosomes (Barbagallo et al. 2018; Wang

341 et al. 2015a; Wang et al. 2006). The expression of $U C A 1$ in plasma decreased in the early stage

342 of AMI but gradually increased in the subsequent process (Yan et al. 2016). This phenomenon is

343 very similar to the LIPCAR aforementioned (Kumarswamy et al. 2014). Given its good indicator

344 role in cancer, we could expect the possibility of its clinical application in AS diagnosis and

345 prognosis.

346

347

348

349

350

351

352

353

354

355

356

357

358

359

360

361

\section{Conclusion}

As a hotspot of non-coding RNAs, lncRNAs have attracted the attention of scholars because of their unique structural characteristics and functions. LncRNAs widely distribute in various organs, tissues, and cells, and have important roles in different types of CVDs, such as CAD, AMI, and so on (Huang 2018). At present, the researches on lncRNAs in the occurrence and development of AS mainly focus on their effects on the lipid metabolism, aberrant proteolysis and cell activities such as impaired function of ECs, modulation of VSMCs' phenotype, recruitment of inflammatory cells, the polarization of macrophages and formation of foam cell (Fasolo et al. 2019; Li et al. 2016; Zhou et al. 2016). In the last several years, the advance of high throughput sequencing technology brought about abundant novel transcripts with or without function annotation. Researchers have classified lncRNAs into different types according to their sequence characteristics, locations on chromosomes, or functions. These classifications could provide brief information on their physical and chemical property. Besides, classification based on its role in biological or pathological processes could facilitate their further researches, especially for those correlated with a specific disease (Jarroux et al. 2017). For example, SALRNAs was classified as Senescence-associated lncRNAs (Abdelmohsen et al. 2013), and 
362

363

364

365

366

367

368

PCA3/PCAT1 as Prostate cancer-associated transcripts (PCATs) (Mitobe et al. 2018). We suggest clustering the lncRNAs reviewed in the present paper into a category of Atherosclerosis-associated circulating lncRNA (ASCLncRNA). Accordingly, the ASCLncRNA should meet the following features: (1) human-sourced long non-coding RNA transcript, (2) detectable in circulating blood, (3) expression level changes with disease development. This definition was limited in human beings because most lncRNAs sequence evolved rapidly and can't be detected as homologues in the different animal models (Necsulea et al. 2014). Further, lncRNA transcripts in this classification have a potentially predictive value for monitoring AS progression. Because of the high incidence and severity of AS in human beings, looking for potential non-invasive diagnostic methods and detectable markers for disease prevention, early diagnosis, and treatment, as well as providing a reliable reference for prognosis and follow-up observations has become an urgent task. Due to the chronic progression of AS, it is also necessary to screen out markers at different stages of disease progression. And the ASCLnRNA transcripts would be candidates. A summary on the characteristics of these ASCLnRNAs is collated in Table 1. Their function, potential mechanisms in human AS-related cells and dynamic changes in the circulating blood was provided here (Fig.1, Fig.2).

The researches on ASCLnRNAs in circulating blood are limited because previous studies just describe the occurrence and variation characteristics of ASCLnRNAs in AS (Chi et al. 2017; Zhang et al. 2019). Before further application of lncRNAs as biomarkers, some questions should be explored and answered. First, current testing methods are still limited, laying the challenges for exploring the origin of lncRNAs in circulating blood. Second, research methods are lacking standardization, and the sample size is often small (Moldovan et al. 2014). Third, some ASCLnRNAs do not only exists in cells related to CVDs but also in some cancer cells, which reduces their potential as independent biomarkers. Last but not least, the expression level of lncRNAs is generally lower than protein-encoding genes, which poses a challenge to the largescale screening for biomarkers with repeatability and reliability (Zhang et al. 2018b). A key factor for future research work is the standardization, including standardized sample extracting and processing methods. Through this way, we could easily compare the different researchers' data and draw reliable conclusions (Kumar et al. 2019). The advent of the latest third-generation full-length transcriptome sequencing technology makes it possible to screen a large number of lncRNAs in different diseases (Mercer et al. 2011). Fortunately, we have seen similar work in 
393

394

395

396

397

398

399

400

401

402

403

404

405

406

407

408

409

410

411

412

413

414

415

416

417

418

419

420

421

422

423

424

425

426

427

428

cancer-related clinical practice. For example, $\operatorname{lnc} R N A-P C A 3$ has been widely recognized as a non-invasive diagnostic marker for prostate cancer (Sanda et al. 2017). Such work provides guidance and reference for finding AS-related biomarkers. The transcripts that meet the criterion of ASCLnRNA could form a candidate repository for further screening and validating researches on biomarkers for AS and could even become new therapeutic targets (Skuratovskaia et al. 2019).

\section{Acknowledgments}

This work was supported by the National Natural Science Foundation of China [grant number 81770462] and the Fundamental Research Funds for the Central Universities of Central South University [2020zzts781].

\section{Conflict of Interests}

The authors declare there is no potential conflict of interests.

\section{References}

Abdelmohsen K, Panda A, Kang MJ, Xu J, Selimyan R, Yoon JH, Martindale JL, De S, Wood WH, 3rd, Becker KG, and Gorospe M. 2013. Senescence-associated lncRNAs: senescence-associated long noncoding RNAs. Aging Cell 12:890-900. 10.1111/acel.12115

Arita T, Ichikawa D, Konishi H, Komatsu S, Shiozaki A, Shoda K, Kawaguchi T, Hirajima S, Nagata H, Kubota T, Fujiwara H, Okamoto K, and Otsuji E. 2013. Circulating long non-coding RNAs in plasma of patients with gastric cancer. Anticancer Res 33:3185-3193.

Arslan S, Berkan O, Lalem T, Ozbilum N, Goksel S, Korkmaz O, Cetin N, Devaux Y, and Cardiolinc n. 2017. Long non-coding RNAs in the atherosclerotic plaque. Atherosclerosis 266:176-181. 10.1016/j.atherosclerosis.2017.10.012

Barbagallo C, Brex D, Caponnetto A, Cirnigliaro M, Scalia M, Magnano A, Caltabiano R, Barbagallo D, Biondi A, Cappellani A, Basile F, Di Pietro C, Purrello M, and Ragusa M. 2018. LncRNA UCA1, Upregulated in CRC Biopsies and Downregulated in Serum Exosomes, Controls mRNA Expression by RNA-RNA Interactions. Mol Ther Nucleic Acids 12:229-241. 10.1016/j.omtn.2018.05.009

Barichievy S, Naidoo J, Boulle M, Scholefield J, Parihar SP, Coussens AK, Brombacher F, Sigal A, and Mhlanga MM. 2018. Viral Apoptosis Evasion via the MAPK Pathway by Use of a Host Long Noncoding RNA. Front Cell Infect Microbiol 8:263. 10.3389/fcimb.2018.00263

Bell RD, Long X, Lin M, Bergmann JH, Nanda V, Cowan SL, Zhou Q, Han Y, Spector DL, Zheng D, and Miano JM. 2014. Identification and initial functional characterization of a human vascular cell-enriched long noncoding RNA. Arterioscler Thromb Vasc Biol 34:1249-1259. 10.1161/ATVBAHA.114.303240

Bochenek G, Hasler R, El Mokhtari NE, Konig IR, Loos BG, Jepsen S, Rosenstiel P, Schreiber S, and Schaefer AS. 2013. The large non-coding RNA ANRIL, which is associated with atherosclerosis, periodontitis and several forms of cancer, regulates ADIPOR1, VAMP3 and C11ORF10. Hum Mol Genet 22:4516-4527. $10.1093 / \mathrm{hmg} / \mathrm{ddt} 299$ 
Boulberdaa M, Scott E, Ballantyne M, Garcia R, Descamps B, Angelini GD, Brittan M, Hunter A, McBride M, McClure J, Miano JM, Emanueli C, Mills NL, Mountford JC, and Baker AH. 2016. A Role for the Long Noncoding RNA SENCR in Commitment and Function of Endothelial Cells. Mol Ther 24:978-990. 10.1038/mt.2016.41

Cai Y, Yang Y, Chen X, He D, Zhang X, Wen X, Hu J, Fu C, Qiu D, Jose PA, Zeng C, and Zhou L. $2016 \mathrm{a}$. Circulating "LncPPARdelta" From Monocytes as a Novel Biomarker for Coronary Artery Diseases. Medicine (Baltimore) 95:e2360. 10.1097/MD.0000000000002360

Cai Y, Yang Y, Chen X, Wu G, Zhang X, Liu Y, Yu J, Wang X, Fu J, Li C, Jose PA, Zeng C, and Zhou L. 2016 b. Circulating 'IncRNA OTTHUMT00000387022' from monocytes as a novel biomarker for coronary artery disease. Cardiovasc Res 112:714-724. 10.1093/cvr/cvw022

Cao L, Zhang Z, Li Y, Zhao P, and Chen Y. 2019. LncRNA H19/miR-let-7 axis participates in the regulation of oxLDL-induced endothelial cell injury via targeting periostin. Int Immunopharmacol 72:496-503. 10.1016/j.intimp.2019.04.042

Cekin N, Ozcan A, Goksel S, Arslan S, Pinarbasi E, and Berkan O. 2018. Decreased FENDRR and LincRNA-p21 expression in atherosclerotic plaque. Anatol J Cardiol 19:131-136. 10.14744/AnatolJCardiol.2017.8081

Chen C, Jin Y, Lo IL, Zhao H, Sun B, Zhao Q, Zheng J, and Zhang XD. 2017. Complexity Change in Cardiovascular Disease. Int J Biol Sci 13:1320-1328. 10.7150/ijbs.19462

Chi JS, Li JZ, Jia JJ, Zhang T, Liu XM, and Yi L. 2017. Long non-coding RNA ANRIL in gene regulation and its duality in atherosclerosis. J Huazhong Univ Sci Technolog Med Sci 37:816-822. 10.1007/s11596-017$1812-y$

Congrains A, Kamide K, Oguro R, Yasuda O, Miyata K, Yamamoto E, Kawai T, Kusunoki H, Yamamoto H, Takeya Y, Yamamoto K, Onishi M, Sugimoto K, Katsuya T, Awata N, Ikebe K, Gondo Y, Oike Y, Ohishi M, and Rakugi H. 2012. Genetic variants at the 9p21 locus contribute to atherosclerosis through modulation of ANRIL and CDKN2A/B. Atherosclerosis 220:449-455. 10.1016/j.atherosclerosis.2011.11.017

Cremer S, Michalik KM, Fischer A, Pfisterer L, Jae N, Winter C, Boon RA, Muhly-Reinholz M, John D, Uchida S, Weber C, Poller W, Gunther S, Braun T, Li DY, Maegdefessel L, Perisic Matic L, Hedin U, Soehnlein O, Zeiher A, and Dimmeler S. 2019. Hematopoietic Deficiency of the Long Noncoding RNA MALAT1 Promotes Atherosclerosis and Plaque Inflammation. Circulation 139:1320-1334. 10.1161/CIRCULATIONAHA.117.029015

de Gonzalo-Calvo D, Kenneweg F, Bang C, Toro R, van der Meer RW, Rijzewijk LJ, Smit JW, Lamb HJ, LlorenteCortes V, and Thum T. 2016a. Circulating long-non coding RNAs as biomarkers of left ventricular diastolic function and remodelling in patients with well-controlled type 2 diabetes. Sci Rep 6:37354. $10.1038 /$ srep37354

de Gonzalo-Calvo D, Kenneweg F, Bang C, Toro R, van der Meer RW, Rijzewijk LJ, Smit JW, Lamb HJ, LlorenteCortes V, and Thum T. 2016b. Circulating Long Noncoding RNAs in Personalized Medicine: Response to Pioglitazone Therapy in Type 2 Diabetes. J Am Coll Cardiol 68:2914-2916. 10.1016/j.jacc.2016.10.014

Dong L, Qi P, Xu MD, Ni SJ, Huang D, Xu QH, Weng WW, Tan C, Sheng WQ, Zhou XY, and Du X. 2015. Circulating CUDR, LSINCT-5 and PTENP1 long noncoding RNAs in sera distinguish patients with gastric cancer from healthy controls. Int J Cancer 137:1128-1135. 10.1002/ijc.29484

Ehrenborg E, and Skogsberg J. 2013. Peroxisome proliferator-activated receptor delta and cardiovascular disease. 
Atherosclerosis 231:95-106. 10.1016/j.atherosclerosis.2013.08.027

Fasolo F, Di Gregoli K, Maegdefessel L, and Johnson JL. 2019. Non-coding RNAs in cardiovascular cell biology and atherosclerosis. Cardiovasc Res 115:1732-1756. 10.1093/cvr/cvz203

Fayda M, Isin M, Tambas M, Guveli M, Meral R, Altun M, Sahin D, Ozkan G, Sanli Y, Isin H, Ozgur E, and Gezer U. 2016. Do circulating long non-coding RNAs (lncRNAs) (LincRNA-p21, GAS 5, HOTAIR) predict the treatment response in patients with head and neck cancer treated with chemoradiotherapy? Tumour Biol 37:3969-3978. 10.1007/s13277-015-4189-1

Folkersen L, Kyriakou T, Goel A, Peden J, Malarstig A, Paulsson-Berne G, Hamsten A, Hugh W, Franco-Cereceda A, Gabrielsen A, Eriksson P, and consortia P. 2009. Relationship between CAD risk genotype in the chromosome 9p21 locus and gene expression. Identification of eight new ANRIL splice variants. PLoS One 4:e7677. 10.1371/journal.pone.0007677

Fridman WH, Zitvogel L, Sautes-Fridman C, and Kroemer G. 2017. The immune contexture in cancer prognosis and treatment. Nat Rev Clin Oncol 14:717-734. 10.1038/nrclinonc.2017.101

Gao H, Wang X, Lin C, An Z, Yu J, Cao H, Fan Y, and Liang X. 2019. Exosomal MALAT1 derived from ox-LDLtreated endothelial cells induce neutrophil extracellular traps to aggravate atherosclerosis. Biol Chem. 10.1515/hsz-2019-0219

Gao W, Zhu M, Wang H, Zhao S, Zhao D, Yang Y, Wang ZM, Wang F, Yang ZJ, Lu X, and Wang LS. 2015. Association of polymorphisms in long non-coding RNA H19 with coronary artery disease risk in a Chinese population. Mutat Res 772:15-22. 10.1016/j.mrfmmm.2014.12.009

Giannoukakis N, Deal C, Paquette J, Goodyer CG, and Polychronakos C. 1993. Parental genomic imprinting of the human IGF2 gene. Nat Genet 4:98-101. 10.1038/ng0593-98

Giordano Attianese GM, and Desvergne B. 2015. Integrative and systemic approaches for evaluating PPARbeta/delta (PPARD) function. Nucl Recept Signal 13:e001. 10.1621/nrs.13001

Gong W, Tian M, Qiu H, and Yang Z. 2017. Elevated serum level of lncRNA-HIF1A-AS1 as a novel diagnostic predictor for worse prognosis in colorectal carcinoma. Cancer Biomark 20:417-424. 10.3233/CBM-170179

Han Y, Ma J, Wang J, and Wang L. 2018a. Silencing of H19 inhibits the adipogenesis and inflammation response in ox-LDL-treated Raw264.7 cells by up-regulating miR-130b. Mol Immunol 93:107-114. 10.1016/j.molimm.2017.11.017

Han Y, Qiu H, Pei X, Fan Y, Tian H, and Geng J. 2018b. Low-dose Sinapic Acid Abates the Pyroptosis of Macrophages by Downregulation of IncRNA-MALAT1 in Rats With Diabetic Atherosclerosis. $J$ Cardiovasc Pharmacol 71:104-112. 10.1097/FJC.0000000000000550

Harada K, Harada K, Uetani T, Kataoka T, Takeshita M, Kunimura A, Takayama Y, Shinoda N, Kato B, Kato M, Marui N, Ishii H, Matsubara T, Amano T, and Murohara T. 2014. The different association of epicardial fat with coronary plaque in patients with acute coronary syndrome and patients with stable angina pectoris: analysis using integrated backscatter intravascular ultrasound. Atherosclerosis 236:301-306. 10.1016/j.atherosclerosis.2014.07.007

Heil B, and Tang WH. 2015. Biomarkers: Their potential in the diagnosis and treatment of heart failure. Cleve Clin J Med 82:S28-35. 10.3949/ccjm.82.s2.05

Hessels D, Klein Gunnewiek JM, van Oort I, Karthaus HF, van Leenders GJ, van Balken B, Kiemeney LA, Witjes JA, and Schalken JA. 2003. DD3(PCA3)-based molecular urine analysis for the diagnosis of prostate cancer. Eur Urol 44:8-15; discussion 15-16. 10.1016/s0302-2838(03)00201-x 
Holdt LM, Beutner F, Scholz M, Gielen S, Gabel G, Bergert H, Schuler G, Thiery J, and Teupser D. 2010. ANRIL expression is associated with atherosclerosis risk at chromosome 9p21. Arterioscler Thromb Vasc Biol 30:620-627. 10.1161/ATVBAHA.109.196832

Holdt LM, Hoffmann S, Sass K, Langenberger D, Scholz M, Krohn K, Finstermeier K, Stahringer A, Wilfert W, Beutner F, Gielen S, Schuler G, Gabel G, Bergert H, Bechmann I, Stadler PF, Thiery J, and Teupser D. 2013. Alu elements in ANRIL non-coding RNA at chromosome 9p21 modulate atherogenic cell functions through trans-regulation of gene networks. PLoS Genet 9:e1003588. 10.1371/journal.pgen.1003588

Holdt LM, and Teupser D. 2012. Recent studies of the human chromosome 9p21 locus, which is associated with atherosclerosis in human populations. Arterioscler Thromb Vasc Biol 32:196-206. 10.1161/ATVBAHA.111.232678

Hu W, Wang Z, Li Q, Wang J, Li L, and Jiang G. 2019a. Upregulation of lincRNA-p21 in thoracic aortic aneurysms is involved in the regulation of proliferation and apoptosis of vascular smooth muscle cells by activating TGF-beta1 signaling pathway. $J$ Cell Biochem 120:4113-4120. 10.1002/jcb.27696

Hu X, Ma R, Fu W, Zhang C, and Du X. 2019b. LncRNA UCA1 sponges miR-206 to exacerbate oxidative stress and apoptosis induced by ox-LDL in human macrophages. $J$ Cell Physiol 234:14154-14160. $10.1002 /$ jcp. 28109

$\mathrm{Hu} \mathrm{Y}$, and $\mathrm{Hu}$ J. 2019. Diagnostic value of circulating lncRNA ANRIL and its correlation with coronary artery disease parameters. Braz J Med Biol Res 52:e8309. 10.1590/1414-431X20198309

Huang Y. 2018. The novel regulatory role of lncRNA-miRNA-mRNA axis in cardiovascular diseases. $J$ Cell Mol Med 22:5768-5775. 10.1111/jcmm.13866

Huarte M, Guttman M, Feldser D, Garber M, Koziol MJ, Kenzelmann-Broz D, Khalil AM, Zuk O, Amit I, Rabani M, Attardi LD, Regev A, Lander ES, Jacks T, and Rinn JL. 2010. A large intergenic noncoding RNA induced by p53 mediates global gene repression in the p53 response. Cell 142:409-419. 10.1016/j.cell.2010.06.040

Ishii N, Ozaki K, Sato H, Mizuno H, Saito S, Takahashi A, Miyamoto Y, Ikegawa S, Kamatani N, Hori M, Saito S, Nakamura Y, and Tanaka T. 2006. Identification of a novel non-coding RNA, MIAT, that confers risk of myocardial infarction. J Hum Genet 51:1087-1099. 10.1007/s10038-006-0070-9

Jarroux J, Morillon A, and Pinskaya M. 2017. History, Discovery, and Classification of lncRNAs. Adv Exp Med Biol 1008:1-46. 10.1007/978-981-10-5203-3_1

Ji P, Diederichs S, Wang W, Boing S, Metzger R, Schneider PM, Tidow N, Brandt B, Buerger H, Bulk E, Thomas M, Berdel WE, Serve H, and Muller-Tidow C. 2003. MALAT-1, a novel noncoding RNA, and thymosin beta4 predict metastasis and survival in early-stage non-small cell lung cancer. Oncogene 22:8031-8041. 10.1038/sj.onc. 1206928

Kanduri C. 2011. Kenq1ot1: a chromatin regulatory RNA. Semin Cell Dev Biol 22:343-350. 10.1016/j.semcdb.2011.02.020

Kumar S, Williams D, Sur S, Wang JY, and Jo H. 2019. Role of flow-sensitive microRNAs and long noncoding RNAs in vascular dysfunction and atherosclerosis. Vascul Pharmacol 114:76-92. 10.1016/j.vph.2018.10.001

Kumarswamy R, Bauters C, Volkmann I, Maury F, Fetisch J, Holzmann A, Lemesle G, de Groote P, Pinet F, and Thum T. 2014. Circulating long noncoding RNA, LIPCAR, predicts survival in patients with heart failure. Circ Res 114:1569-1575. 10.1161/CIRCRESAHA.114.303915 
552

553

554

555

556

557

558

559

560

561

562

563

564

565

566

567

568

569

570

571

572

573

574

575

576

577

578

579

580

581

582

583

584

585

586

587

588

589

590

591

592

Li H, Zhu H, and Ge J. 2016. Long Noncoding RNA: Recent Updates in Atherosclerosis. Int J Biol Sci 12:898-910. $10.7150 /$ ijbs. 14430

Li H, Zhu X, Hu L, Li Q, Ma J, and Yan J. 2019. Loss of exosomal MALAT1 from ox-LDL-treated vascular endothelial cells induces maturation of dendritic cells in atherosclerosis development. Cell Cycle 18:22552267. 10.1080/15384101.2019.1642068

Li M, Wang YF, Yang XC, Xu L, Li WM, Xia K, Zhang DP, Wu RN, and Gan T. 2018a. Circulating Long Noncoding RNA LIPCAR Acts as a Novel Biomarker in Patients with ST-Segment Elevation Myocardial Infarction. Med Sci Monit 24:5064-5070. 10.12659/MSM.909348

Li S, Sun Y, Zhong L, Xiao Z, Yang M, Chen M, Wang C, Xie X, and Chen X. 2018b. The suppression of ox-LDLinduced inflammatory cytokine release and apoptosis of HCAECs by long non-coding RNA-MALAT1 via regulating microRNA-155/SOCS1 pathway. Nutr Metab Cardiovasc Dis 28:1175-1187. 10.1016/j.numecd.2018.06.017

Li Z, Li X, Wu S, Xue M, and Chen W. 2014. Long non-coding RNA UCA1 promotes glycolysis by upregulating hexokinase 2 through the mTOR-STAT3/microRNA143 pathway. Cancer Sci 105:951-955. $10.1111 /$ cas. 12461

Liang W, Lv T, Shi X, Liu H, Zhu Q, Zeng J, Yang W, Yin J, and Song Y. 2016. Circulating long noncoding RNA GAS5 is a novel biomarker for the diagnosis of nonsmall cell lung cancer. Medicine (Baltimore) 95:e4608. 10.1097/MD.0000000000004608

Libby P, Ridker PM, and Hansson GK. 2011. Progress and challenges in translating the biology of atherosclerosis. Nature 473:317-325. 10.1038/nature10146

Lyu Q, Xu S, Lyu Y, Choi M, Christie CK, Slivano OJ, Rahman A, Jin ZG, Long X, Xu Y, and Miano JM. 2019. SENCR stabilizes vascular endothelial cell adherens junctions through interaction with CKAP4. Proc Natl Acad Sci U S A 116:546-555. 10.1073/pnas.1810729116

Meng F, Yan J, Ma Q, Jiao Y, Han L, Xu J, Yang F, and Liu J. 2018. Expression status and clinical significance of lncRNA APPAT in the progression of atherosclerosis. PeerJ 6:e4246. 10.7717/peerj.4246

Mercer TR, Gerhardt DJ, Dinger ME, Crawford J, Trapnell C, Jeddeloh JA, Mattick JS, and Rinn JL. 2011. Targeted RNA sequencing reveals the deep complexity of the human transcriptome. Nat Biotechnol 30:99-104. 10.1038/nbt.2024

Michalik KM, You X, Manavski Y, Doddaballapur A, Zornig M, Braun T, John D, Ponomareva Y, Chen W, Uchida S, Boon RA, and Dimmeler S. 2014. Long noncoding RNA MALAT1 regulates endothelial cell function and vessel growth. Circ Res 114:1389-1397. 10.1161/CIRCRESAHA.114.303265

Mitobe Y, Takayama KI, Horie-Inoue K, and Inoue S. 2018. Prostate cancer-associated IncRNAs. Cancer Lett 418:159-166. 10.1016/j.canlet.2018.01.012

Moldovan L, Batte KE, Trgovcich J, Wisler J, Marsh CB, and Piper M. 2014. Methodological challenges in utilizing miRNAs as circulating biomarkers. $J$ Cell Mol Med 18:371-390. 10.1111/jcmm.12236

Monteiro JP, Bennett M, Rodor J, Caudrillier A, Ulitsky I, and Baker AH. 2019. Endothelial function and dysfunction in the cardiovascular system: the long non-coding road. Cardiovasc Res 115:1692-1704. $10.1093 / \mathrm{cvr} / \mathrm{cvz} 154$

Necsulea A, Soumillon M, Warnefors M, Liechti A, Daish T, Zeller U, Baker JC, Grutzner F, and Kaessmann H. 2014. The evolution of IncRNA repertoires and expression patterns in tetrapods. Nature 505:635-640. $10.1038 /$ nature 12943 
NHLBI. 2020. Atherosclerosis. Available at https://www.nhlbi.nih.gov/health-topics/atherosclerosis.

Pahwa. R, and Jialal. I. 2019. Atherosclerosis: StatPearls Publishing.

Palazzo AF, and Lee ES. 2015. Non-coding RNA: what is functional and what is junk? Front Genet 6:2. 10.3389/fgene.2015.00002

Pan JX. 2017. LncRNA H19 promotes atherosclerosis by regulating MAPK and NF-kB signaling pathway. Eur Rev Med Pharmacol Sci 21:322-328.

Pan Z, Fan Z, Ma J, Liu H, Shen L, He B, and Zhang M. 2019. Profiling and functional characterization of circulation LncRNAs that are associated with coronary atherosclerotic plaque stability. Am J Transl Res 11:3801-3815.

Panzitt K, Tschernatsch MM, Guelly C, Moustafa T, Stradner M, Strohmaier HM, Buck CR, Denk H, Schroeder R, Trauner M, and Zatloukal K. 2007. Characterization of HULC, a novel gene with striking up-regulation in hepatocellular carcinoma, as noncoding RNA. Gastroenterology 132:330-342. 10.1053/j.gastro.2006.08.026

Pasmant E, Laurendeau I, Heron D, Vidaud M, Vidaud D, and Bieche I. 2007. Characterization of a germ-line deletion, including the entire INK4/ARF locus, in a melanoma-neural system tumor family: identification of ANRIL, an antisense noncoding RNA whose expression coclusters with ARF. Cancer Res 67:3963-3969. 10.1158/0008-5472.CAN-06-2004

Pasmant E, Sabbagh A, Vidaud M, and Bieche I. 2011. ANRIL, a long, noncoding RNA, is an unexpected major hotspot in GWAS. FASEB J 25:444-448. 10.1096/fj.10-172452

Paulsen M, Davies KR, Bowden LM, Villar AJ, Franck O, Fuermann M, Dean WL, Moore TF, Rodrigues N, Davies KE, Hu RJ, Feinberg AP, Maher ER, Reik W, and Walter J. 1998. Syntenic organization of the mouse distal chromosome 7 imprinting cluster and the Beckwith-Wiedemann syndrome region in chromosome 11p15.5. Hum Mol Genet 7:1149-1159. 10.1093/hmg/7.7.1149

Qi P, Zhou XY, and Du X. 2016. Circulating long non-coding RNAs in cancer: current status and future perspectives. Mol Cancer 15:39. 10.1186/s12943-016-0524-4

Reis EM, and Verjovski-Almeida S. 2012. Perspectives of Long Non-Coding RNAs in Cancer Diagnostics. Front Genet 3:32. 10.3389/fgene.2012.00032

Roth A, and Diederichs S. 2016. Long Noncoding RNAs in Lung Cancer. Curr Top Microbiol Immunol 394:57-110. $10.1007 / 82 \_2015 \_444$

Salmena L, Poliseno L, Tay Y, Kats L, and Pandolfi PP. 2011. A ceRNA hypothesis: the Rosetta Stone of a hidden RNA language? Cell 146:353-358. 10.1016/j.cell.2011.07.014

Sanada F, Taniyama Y, Muratsu J, Otsu R, Shimizu H, Rakugi H, and Morishita R. 2018. Gene-Therapeutic Strategies Targeting Angiogenesis in Peripheral Artery Disease. Medicines (Basel) 5. 10.3390/medicines5020031

Sanda MG, Feng Z, Howard DH, Tomlins SA, Sokoll LJ, Chan DW, Regan MM, Groskopf J, Chipman J, Patil DH, Salami SS, Scherr DS, Kagan J, Srivastava S, Thompson IM, Jr., Siddiqui J, Fan J, Joon AY, Bantis LE, Rubin MA, Chinnayian AM, Wei JT, and the E-PCASG, Bidair M, Kibel A, Lin DW, Lotan Y, Partin A, and Taneja S. 2017. Association Between Combined TMPRSS2:ERG and PCA3 RNA Urinary Testing and Detection of Aggressive Prostate Cancer. JAMA Oncol 3:1085-1093. 10.1001/jamaoncol.2017.0177

Santer L, Lopez B, Ravassa S, Baer C, Riedel I, Chatterjee S, Moreno MU, Gonzalez A, Querejeta R, Pinet F, Thum T, and Diez J. 2019. Circulating Long Noncoding RNA LIPCAR Predicts Heart Failure Outcomes in 
634

635

636

637

638

639

640

641

642

643

644

645

646

647

648

649

650

651

652

653

654

655

656

657

658

659

660

661

662

663

664

665

666

667

668

669

670

671

672

673

674

Patients Without Chronic Kidney Disease. Hypertension 73:820-828. 10.1161/HYPERTENSIONAHA.118.12261

Saxena A, and Carninci P. 2011. Long non-coding RNA modifies chromatin: epigenetic silencing by long noncoding RNAs. Bioessays 33:830-839. 10.1002/bies.201100084

Schulte C, Barwari T, Joshi A, Theofilatos K, Zampetaki A, Barallobre-Barreiro J, Singh B, Sorensen NA, Neumann JT, Zeller T, Westermann D, Blankenberg S, Marber M, Liebetrau C, and Mayr M. 2019. Comparative Analysis of Circulating Noncoding RNAs Versus Protein Biomarkers in the Detection of Myocardial Injury. Circ Res 125:328-340. 10.1161/CIRCRESAHA.119.314937

Shahmoradi N, Nasiri M, Kamfiroozi H, and Kheiry MA. 2017. Association of the rs555172 polymorphism in SENCR long non-coding RNA and atherosclerotic coronary artery disease. $J$ Cardiovasc Thorac Res 9:170-174. 10.15171/jevtr.2017.29

Shi Q, and Yang X. 2016. Circulating MicroRNA and Long Noncoding RNA as Biomarkers of Cardiovascular Diseases. J Cell Physiol 231:751-755. 10.1002/jcp.25174

Skuratovskaia D, Vulf M, Komar A, Kirienkova E, and Litvinova L. 2019. Promising Directions in Atherosclerosis Treatment Based on Epigenetic Regulation Using MicroRNAs and Long Noncoding RNAs. Biomolecules 9. 10.3390/biom9060226

Tantai J, Hu D, Yang Y, and Geng J. 2015. Combined identification of long non-coding RNA XIST and HIF1AAS1 in serum as an effective screening for non-small cell lung cancer. Int J Clin Exp Pathol 8:7887-7895.

Teng L, and Meng R. 2019. Long Non-Coding RNA MALAT1 Promotes Acute Cerebral Infarction Through miRNAs-Mediated hs-CRP Regulation. J Mol Neurosci 69:494-504. 10.1007/s12031-019-01384-y

Tinzl M, Marberger M, Horvath S, and Chypre C. 2004. DD3PCA3 RNA analysis in urine--a new perspective for detecting prostate cancer. Eur Urol 46:182-186; discussion 187. 10.1016/j.eururo.2004.06.004

Tong YS, Wang XW, Zhou XL, Liu ZH, Yang TX, Shi WH, Xie HW, Lv J, Wu QQ, and Cao XF. 2015. Identification of the long non-coding RNA POU3F3 in plasma as a novel biomarker for diagnosis of esophageal squamous cell carcinoma. Mol Cancer 14:3. 10.1186/1476-4598-14-3

Vausort M, Wagner DR, and Devaux Y. 2014. Long noncoding RNAs in patients with acute myocardial infarction. Circ Res 115:668-677. 10.1161/CIRCRESAHA.115.303836

Wang F, Li X, Xie X, Zhao L, and Chen W. 2008. UCA1, a non-protein-coding RNA up-regulated in bladder carcinoma and embryo, influencing cell growth and promoting invasion. FEBS Lett 582:1919-1927. 10.1016/j.febslet.2008.05.012

Wang HM, Lu JH, Chen WY, and Gu AQ. 2015a. Upregulated lncRNA-UCA1 contributes to progression of lung cancer and is closely related to clinical diagnosis as a predictive biomarker in plasma. Int J Clin Exp Med 8:11824-11830.

Wang J, Chen L, Li H, Yang J, Gong Z, Wang B, and Zhao X. 2015b. Clopidogrel reduces apoptosis and promotes proliferation of human vascular endothelial cells induced by palmitic acid via suppression of the long noncoding RNA HIF1A-AS1 in vitro. Mol Cell Biochem 404:203-210. 10.1007/s11010-015-2379-1

Wang J, Wu X, Tian Y, Li X, Zhao X, and Zhang M. 2018. Dynamic changes and diagnostic and prognostic significance of serum PCT, hs-CRP and s-100 protein in central nervous system infection. Exp Ther Med 16:5156-5160. 10.3892/etm.2018.6866

Wang JJ, Wang X, Song YX, Zhao JH, Sun JX, Shi JX, Wu ZH, and Wang ZN. 2019a. Circulating Noncoding RNAs Have a Promising Future Acting as Novel Biomarkers for Colorectal Cancer. Dis Markers 
2019:2587109. 10.1155/2019/2587109

Wang K, Yang C, Shi J, and Gao T. 2019b. Ox-LDL-induced lncRNA MALAT1 promotes autophagy in human umbilical vein endothelial cells by sponging miR-216a-5p and regulating Beclin-1 expression. Eur $J$ Pharmacol 858:172338. 10.1016/j.ejphar.2019.04.019

Wang S, Zhang X, Yuan Y, Tan M, Zhang L, Xue X, Yan Y, Han L, and Xu Z. 2015c. BRG1 expression is increased in thoracic aortic aneurysms and regulates proliferation and apoptosis of vascular smooth muscle cells through the long non-coding RNA HIF1A-AS1 in vitro. Eur J Cardiothorac Surg 47:439-446. 10.1093/ejcts/ezu215

Wang X, Li D, Chen H, Wei X, and Xu X. 2019c. Expression of Long Noncoding RNA LIPCAR Promotes Cell Proliferation, Cell Migration, and Change in Phenotype of Vascular Smooth Muscle Cells. Med Sci Monit 25:7645-7651. 10.12659/MSM.915681

Wang XS, Zhang Z, Wang HC, Cai JL, Xu QW, Li MQ, Chen YC, Qian XP, Lu TJ, Yu LZ, Zhang Y, Xin DQ, Na YQ, and Chen WF. 2006. Rapid identification of UCA1 as a very sensitive and specific unique marker for human bladder carcinoma. Clin Cancer Res 12:4851-4858. 10.1158/1078-0432.CCR-06-0134

Wang Y, Liang J, Xu J, Wang X, Zhang X, Wang W, Chen L, and Yuan T. 2017. Circulating exosomes and exosomal lncRNA HIF1A-AS1 in atherosclerosis. Int J Clin Exp Pathol 10:8383-8388.

Wapinski O, and Chang HY. 2011. Long noncoding RNAs and human disease. Trends Cell Biol 21:354-361. 10.1016/j.tcb.2011.04.001

WHO. 2017. Cardiovascular Diseases. Available at https://www.who.int/health-topics/cardiovasculardiseases/\#tab=tab_1.

Wu G, Cai J, Han Y, Chen J, Huang ZP, Chen C, Cai Y, Huang H, Yang Y, Liu Y, Xu Z, He D, Zhang X, Hu X, Pinello L, Zhong D, He F, Yuan GC, Wang DZ, and Zeng C. 2014. LincRNA-p21 regulates neointima formation, vascular smooth muscle cell proliferation, apoptosis, and atherosclerosis by enhancing p53 activity. Circulation 130:1452-1465. 10.1161/CIRCULATIONAHA.114.011675

Xi B, Shen Y, Reilly KH, Wang X, and Mi J. 2013. Recapitulation of four hypertension susceptibility genes (CSK, CYP17A1, MTHFR, and FGF5) in East Asians. Metabolism 62:196-203. 10.1016/j.metabol.2012.07.008

Xu J, Zhang Y, Chu L, Chen W, Du Y, and Gu J. 2019. Long non-coding RNA HIF1A-AS1 is upregulated in intracranial aneurysms and participates in the regulation of proliferation of vascular smooth muscle cells by upregulating TGF-beta1. Exp Ther Med 17:1797-1801. 10.3892/etm.2018.7144

Yan B, Yao J, Liu JY, Li XM, Wang XQ, Li YJ, Tao ZF, Song YC, Chen Q, and Jiang Q. 2015. IncRNA-MIAT regulates microvascular dysfunction by functioning as a competing endogenous RNA. Circ Res 116:11431156. 10.1161/CIRCRESAHA.116.305510

Yan Y, Zhang B, Liu N, Qi C, Xiao Y, Tian X, Li T, and Liu B. 2016. Circulating Long Noncoding RNA UCA1 as a Novel Biomarker of Acute Myocardial Infarction. Biomed Res Int 2016:8079372. 10.1155/2016/8079372

Yang L, Lin C, Liu W, Zhang J, Ohgi KA, Grinstein JD, Dorrestein PC, and Rosenfeld MG. 2011. ncRNA- and Pc2 methylation-dependent gene relocation between nuclear structures mediates gene activation programs. Cell 147:773-788. 10.1016/j.cell.2011.08.054

Yang Y, Cai Y, Wu G, Chen X, Liu Y, Wang X, Yu J, Li C, Chen X, Jose PA, Zhou L, and Zeng C. 2015. Plasma long non-coding RNA, CoroMarker, a novel biomarker for diagnosis of coronary artery disease. Clin Sci (Lond) 129:675-685. 10.1042/CS20150121

Ye ZM, Yang S, Xia YP, Hu RT, Chen S, Li BW, Chen SL, Luo XY, Mao L, Li Y, Jin H, Qin C, and Hu B. 2019. 
LncRNA MIAT sponges miR-149-5p to inhibit efferocytosis in advanced atherosclerosis through CD47 upregulation. Cell Death Dis 10:138. 10.1038/s41419-019-1409-4

Yin D, Fu C, and Sun D. 2018. Silence of lncRNA UCA1 Represses the Growth and Tube Formation of Human Microvascular Endothelial Cells Through miR-195. Cell Physiol Biochem 49:1499-1511. $10.1159 / 000493454$

Yu F, Zhou G, Huang K, Fan X, Li G, Chen B, Dong P, and Zheng J. 2017. Serum lincRNA-p21 as a potential biomarker of liver fibrosis in chronic hepatitis B patients. J Viral Hepat 24:580-588. 10.1111/jvh.12680

Zhang K, Luo Z, Zhang Y, Zhang L, Wu L, Liu L, Yang J, Song X, and Liu J. 2016. Circulating IncRNA H19 in plasma as a novel biomarker for breast cancer. Cancer Biomark 17:187-194. 10.3233/CBM-160630

Zhang L, Cheng H, Yue Y, Li S, Zhang D, and He R. 2018a. H19 knockdown suppresses proliferation and induces apoptosis by regulating miR-148b/WNT/beta-catenin in ox-LDL -stimulated vascular smooth muscle cells. J Biomed Sci 25:11. 10.1186/s12929-018-0418-4

Zhang L, and Wang YM. 2019. Expression and function of lncRNA ANRIL in a mouse model of acute myocardial infarction combined with type 2 diabetes mellitus. $J$ Chin Med Assoc 82:685-692. 10.1097/JCMA.0000000000000182

Zhang Y, Zhang L, Wang Y, Ding H, Xue S, Yu H, Hu L, Qi H, Wang Y, Zhu W, Liu D, and Li P. 2019. KCNQ1OT1, HIF1A-AS2 and APOA1-AS are promising novel biomarkers for diagnosis of coronary artery disease. Clin Exp Pharmacol Physiol 46:635-642. 10.1111/1440-1681.13094

Zhang Z, Gao W, Long QQ, Zhang J, Li YF, Liu DC, Yan JJ, Yang ZJ, and Wang LS. 2017. Increased plasma levels of lncRNA H19 and LIPCAR are associated with increased risk of coronary artery disease in a Chinese population. Sci Rep 7:7491. 10.1038/s41598-017-07611-z

Zhang Z, Salisbury D, and Sallam T. 2018b. Long Noncoding RNAs in Atherosclerosis: JACC Review Topic of the Week. J Am Coll Cardiol 72:2380-2390. 10.1016/j.jacc.2018.08.2161

Zhao Y, Feng G, Wang Y, Yue Y, and Zhao W. 2014. Regulation of apoptosis by long non-coding RNA HIF1AAS1 in VSMCs: implications for TAA pathogenesis. Int J Clin Exp Pathol 7:7643-7652.

Zhong X, Ma X, Zhang L, Li Y, Li Y, and He R. 2018. MIAT promotes proliferation and hinders apoptosis by modulating miR-181b/STAT3 axis in ox-LDL-induced atherosclerosis cell models. Biomed Pharmacother 97:1078-1085. 10.1016/j.biopha.2017.11.052

Zhou J, Zhang M, Fang H, El-Mounayri O, Rodenberg JM, Imbalzano AN, and Herring BP. 2009. The SWI/SNF chromatin remodeling complex regulates myocardin-induced smooth muscle-specific gene expression. Arterioscler Thromb Vasc Biol 29:921-928. 10.1161/ATVBAHA.109.187229

Zhou T, Ding JW, Wang XA, and Zheng XX. 2016. Long noncoding RNAs and atherosclerosis. Atherosclerosis 248:51-61. 10.1016/j.atherosclerosis.2016.02.025

PeerJ reviewing PDF | (2020:02:46064:2:1:NEW 27 Aug 2020) 


\section{Figure 1}

Functional mechanisms of Atherosclerosis-associated circulating IncRNA (ASCIncRNA).

ECs: endothelial cells; VSMCs: vascular smooth muscle cells. 


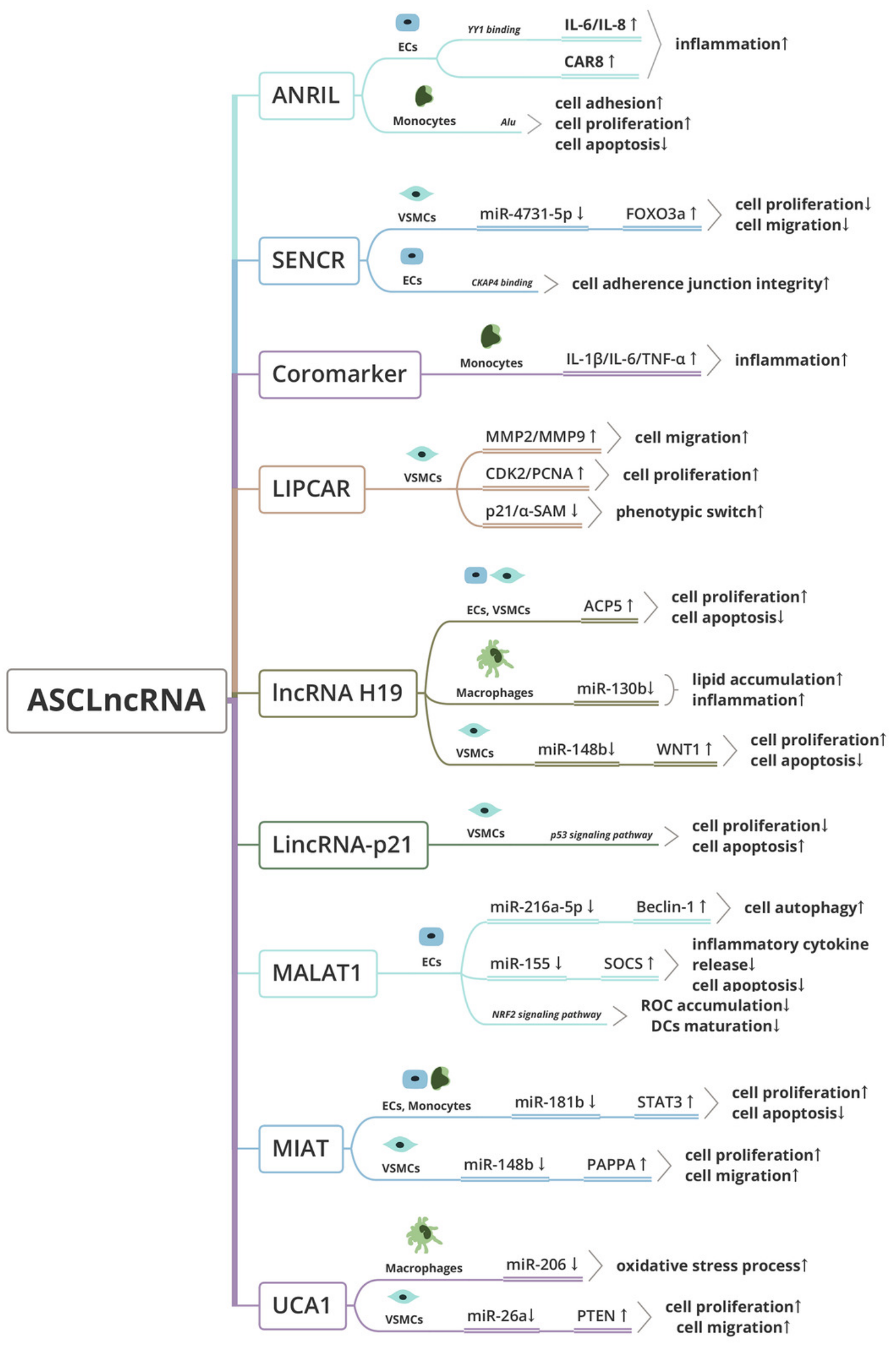


Figure 2

The dynamic changes of Atherosclerosis-associated circulating IncRNA (ASCLncRNA) in blood. 


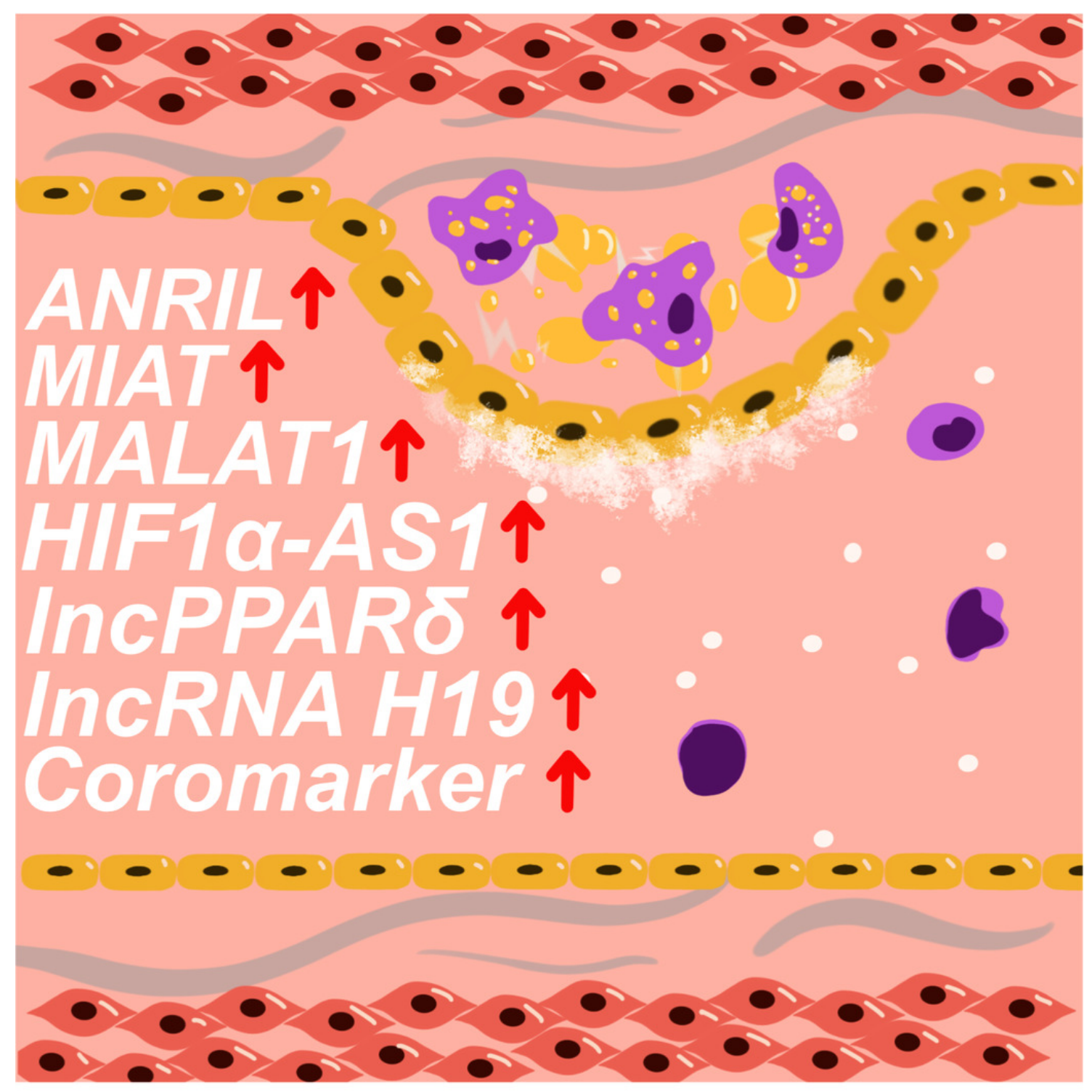




\section{Table $\mathbf{1}$ (on next page)}

Summary of atherosclerosis-associated circulating IncRNA (ASCIncRNA).

*The data of specificity/sensitivity percentages were derived directly from the ROC analysis of the original text. AMI: acute myocardial infarction; AS: atherosclerosis; CAD: coronary artery disease; HF: heart failure. 


\begin{tabular}{|c|c|c|c|c|c|c|c|c|c|}
\hline $\begin{array}{l}\text { ASCLncR } \\
\text { NA }\end{array}$ & Official Full Name & $\begin{array}{l}\text { Gene ID } \\
\text { (NCBI/Ensembl) }\end{array}$ & Category & Location & $\begin{array}{l}\text { Atherogenic/ } \\
\text { atheroprotective }\end{array}$ & $\begin{array}{l}\text { Disease } \\
\text { type }\end{array}$ & sensitivity* & specificity* & PMID \\
\hline ANRIL & $\begin{array}{l}\text { CDmfKN2B antisense } \\
\text { RNA } 1\end{array}$ & $\begin{array}{l}100048912 / \\
\text { ENSG0000024049 } \\
8\end{array}$ & antisense & $9 p 21.3$ & atherogenic & AMI/AS & $\begin{array}{l}81.6 \%- \\
90.2 \%\end{array}$ & $\begin{array}{l}59.7 \%- \\
65.7 \%\end{array}$ & $\begin{array}{l}30234067 ; \\
31411246 ; \\
23861667\end{array}$ \\
\hline SENCR & $\begin{array}{l}\text { Smooth muscle and } \\
\text { endothelial cell enriched } \\
\text { migration/differentiation- } \\
\text { associated IncRNA }\end{array}$ & $\begin{array}{l}100507392 / \\
\text { ENSG0000025470 } \\
3\end{array}$ & antisense & $11 q 24.3$ & atheroprotective & AS & - & - & 30584103 \\
\hline CoroMarker & $\begin{array}{l}\text { Aldo-keto reductase } \\
\text { family } 1 \text { member B1 } \\
\text { pseudogene } 3\end{array}$ & $\begin{array}{l}\text { 729347/ENSG0000 } \\
0213785\end{array}$ & intergenic & $11 \mathrm{p} 15.2$ & atherogenic & CAD & $76 \%$ & $92.5 \%$ & 26857419 \\
\hline LIPCAR & $\begin{array}{l}\text { Mitochondrially encoded } \\
\text { long non-coding cardiac } \\
\text { associated RNA }\end{array}$ & - & antisense & - & atherogenic & $\mathrm{CAD} / \mathrm{HF}$ & $72.2 \%$ & $62.3 \%$ & $\begin{array}{l}31603865 ; \\
28790415\end{array}$ \\
\hline HIF1A-AS1 & HIF1A antisense RNA 1 & - & antisense & $14 q 23.2$ & unknown & AS & - & & 24875884 \\
\hline $\begin{array}{l}\text { LncRNA } \\
\text { H19 }\end{array}$ & $\begin{array}{l}\text { H19 imprinted maternally } \\
\text { expressed transcript }\end{array}$ & $\begin{array}{l}283120 / \\
\text { ENSG0000013060 } \\
0\end{array}$ & intergenic & $11 \mathrm{p} 15.5$ & atherogenic & AS & $53.6 \%$ & $73 \%$ & $\begin{array}{l}30778327 ; \\
28165553 ; \\
28790415\end{array}$ \\
\hline APPAT & - & ENST00000620272 & intergenic & & unknown & AMI & $78.72 \%$ & $93.02 \%$ & 29372117 \\
\hline
\end{tabular}




\begin{tabular}{|c|c|c|c|c|c|c|c|c|c|}
\hline $\begin{array}{l}\text { KCNQ1OT } \\
1\end{array}$ & $\begin{array}{l}\text { KCNQ1 opposite } \\
\text { strand/antisense } \\
\text { transcript } 1\end{array}$ & $\begin{array}{l}10984 / \\
\text { ENSG0000026982 } \\
1\end{array}$ & antisense & $11 \mathrm{p} 15.5$ & unknown & $\begin{array}{l}\text { AMI/CA } \\
\text { D/AS }\end{array}$ & $100 \%$ & $60 \%$ & 30941792 \\
\hline LncPPARס & - & - & intergenic & - & unknown & CAD & $70 \%-82 \%$ & $78 \%-94 \%$ & 26871769 \\
\hline $\begin{array}{l}\text { LincRNA- } \\
\text { p21 }\end{array}$ & $\begin{array}{l}\text { Tumor protein p53 } \\
\text { pathway corepressor } 1\end{array}$ & 102800311 & intergenic & $6 p 21.2$ & atheroprotective & AS & - & - & 25156994 \\
\hline MALAT1 & $\begin{array}{l}\text { Metastasis associated } \\
\text { lung adenocarcinoma } \\
\text { transcript } 1\end{array}$ & $\begin{array}{l}378938 / \\
\text { ENSG0000025156 } \\
2\end{array}$ & intergenic & $11 q 13.1$ & atheroprotective & AS & $50 \%$ & $63.6 \%$ & $\begin{array}{l}30586743 \\
31188931\end{array}$ \\
\hline MIAT & $\begin{array}{l}\text { Myocardial infarction } \\
\text { associated transcript }\end{array}$ & $\begin{array}{l}440823 / \\
\text { ENSG0000022578 } \\
3\end{array}$ & intergenic & $22 q 12.1$ & atherogenic & AS & 0.955 & 0.727 & $\begin{array}{l}31237148 \\
31188931\end{array}$ \\
\hline UCA1 & $\begin{array}{l}\text { Urothelial cancer } \\
\text { associated } 1\end{array}$ & $\begin{array}{l}652995 / \\
\text { ENSG0000021404 } \\
9\end{array}$ & intergenic & 19p13.12 & atherogenic & AMI & - & - & 30633352 \\
\hline
\end{tabular}

2 